\title{
The Relationship Between Parent-Reported Coping, Stress, and Mental Health in a Preschool Population
}

\author{
Neisha Kiernan, ${ }^{1}$ Erica Frydenberg, ${ }^{1}$ Jan Deans ${ }^{2}$ and Rachel Liang ${ }^{1}$ \\ ${ }^{1}$ The University of Melbourne, Melbourne Graduate School of Education, Victoria, Australia \\ ${ }^{2}$ The University of Melbourne, Early Learning Centre, Victoria, Australia
}

The present study explored the component structure of coping in preschoolers as measured by the Children's Coping Scale - Revised (CCS-R) through principal component analysis (PCA). The study also examined the relationship between different coping patterns and mental health (as measured by the Strengths and Difficulties Questionnaire; SDQ) in preschoolers. One hundred and thirty-two parents of preschoolers enrolled at a university-affiliated Early Learning Centre in Melbourne, Australia completed the CCS-R and the SDQ as part of a larger project. The PCAs found that a three-component structure of coping in preschoolers best fit the data for all general and situation-specific forms of the CCS-R. The majority of the forms, for both mothers and fathers, resulted in the components of: (1) Positive Coping, (2) Negative Coping Emotional Inhibition, and (3) Negative Coping - Emotional Expression. The Situation Specific Coping forms resulted in the most reliable components, and the items that loaded on each component were the most consistent with previous research, underscoring a need to focus on situation-specific, as opposed to general, coping in preschoolers. Results for the relationship between the CCS-R and the SDQ found associations between positive coping and positive mental health, and negative coping was associated with some aspects of poor mental health. The patterns of associations provide evidence of construct validity for the component structure of the CCS-R and also highlight opportunities for intervention for this age group. Understanding the processes involved in managing and adapting to stress provides the opportunity to develop prevention and intervention approaches targeted at healthy adaption. Coping in preschoolers, and the degree to which preschoolers' coping is associated with mental health, is largely under-studied in comparison to other life stages. The present study contributes to this small body of research in an effort to help inform teaching and therapeutic approaches for preschoolers.

Keywords: coping, stress, mental health, preschoolers, Children's Coping Scale - Revised (CCS-R), Strengths and Difficulties Questionnaire (SDQ)

Received 30 August 2017; Accepted 25 October 2017

Address for correspondence: Neisha Kiernan, The University of Melbourne, Melbourne Graduate School of Education, 34 Queensberry Street, Parkville VIC 3053, Australia. Email: n.kiernan@student.unimelb.edu.au. 
Stress and coping are among the most highly researched areas in psychology (Frydenberg, 2014; Hobfoll, 1989; Somerfield \& McCrae, 2000). How people cope with stress can either reduce or increase the impact of stressful circumstances on their short-term wellbeing and functioning and also longer-term physical and mental health (Skinner, Edge, Altman, \& Sherwood, 2003). Understanding how coping skills develop in children furthers our knowledge of the processes that underlie adaption to stress (Compas, Connor-Smith, Saltzman, Thomsen, \& Wadsworth, 2001).

In general, there is consistency in the research on coping and mental health: how a person copes with stress predicts their mental health and psychological adjustment (Compas et al., 2001; Frydenberg \& Lewis, 2009; Holen, Lervåg, Waaktaar, \& Ystgaard, 2012; Wright, Banerjee, Hoek, Rieffe, \& Novin, 2010). There is, however, a paucity of research pertaining to non-clinical populations and the early years. It is important to understand patterns of coping in young children that are associated with different mental health profiles to be able to best inform prevention and intervention approaches.

\section{Coping in Children}

The adoption of typical ways of coping in childhood may place individuals on developmental trajectories that either put them at risk or protect them during adolescence and adulthood (Compas et al., 2001). Understanding how children cope can help educators, parents, and other professionals better support the healthy development of children and set them on developmental trajectories to thrive rather than just survive the ups and downs of life. Research suggesting that coping in children is malleable, while coping in adults is more trait-like and stable (Wadsworth, Raviv, Compas, \& Connor-Smith, 2005), further highlights the importance of children's coping research and intervention.

Coping in children needs to be studied within the context of development, where children's coping is clearly constrained by their social, emotional, and cognitive development (Compas, 1998; Skinner \& Zimmer-Gembeck, 2009). For example, Skinner and Zimmer-Gembeck $(2007,2009)$ identified 'developmental shifts' in young children's coping, ranging from reflexive and reactive coping in the early years to cognitive responses in middle childhood. Coping continues to change in quality throughout childhood and into adolescence as children develop physically and neurologically, and the social worlds and stressors they are exposed to also change (Skinner \& ZimmerGembeck, 2009).

Growing research suggests that typical adult dichotomies may not be appropriate for children's coping. For example, Ayers, Sandier, West, and Roosa (1996) assessed coping in children in Grades 4-6 and found that the models of problem- versus emotion-focused coping and active versus passive coping were not a good fit for the data, as analysed by confirmatory factor analysis (CFA). The best fit was a four-factor model of active, distraction, avoidance, and support-seeking coping. Other studies also do not result in categories consistent with adult research; for example, Walker, Smith, Garber, and Van Slyke (1997) identified three factors of coping in a measure of paediatric pain (the children were aged 9 to 12): active, passive, and accommodative (emotion-focused) coping.

Additionally, similar to adult coping, research on the taxonomies of coping in children remains inconclusive. For example, Compas and colleagues' (2001) metareview of over 60 published studies on stress and coping in children concluded that 
there was no clear consensus on coping dimensions within their reviewed studies. Variations within studies of children's coping may be due to developmental differences in the children studied, with different outcomes possibly reflecting the changes in quality and quantity of coping strategies employed by children of different ages. With this in mind, it is important to study coping within the context of the different age groups in childhood and adolescence, including the currently under-studied early years.

Children as young as 4 years old are able to identify and use coping strategies to regulate their behaviour and emotions. For example, it was found that 4- to 5-yearolds were able to spontaneously describe up to 36 different coping responses (Deans, Frydenberg, \& Tsurutani, 2010). Notably, the children reported using more active coping strategies (e.g., try and fix it) and fewer passive coping strategies (e.g., cry or scream) than those identified by the children's parents; parents and children reported similar use of relational coping strategies (e.g., get help from a grown-up; Deans et al., 2010). Further to this, Chalmers, Frydenberg, and Deans (2011) interviewed 4 -year-olds around their coping strategies when dealing with seven age-appropriate challenging situations. The children identified a range of coping strategies that were clustered into productive (e.g., play/do something else) and non-productive (e.g., do nothing/don't know) coping (Chalmers et al., 2011). Findings from Chalmers and colleagues suggests that by 4 years of age children have not only developed a repertoire of coping skills, but some of these are already non-productive, making interventions to increase productive coping and unlearn non-productive coping important for this age group. Additionally, the research on coping in preschoolers suggests that who you ask, and how you ask, makes a difference to the strategies identified.

Yeo et al. (2014) explored the 29-item, parent-rated Children's Coping Scale Revised (CCS-R) General Coping form with a sample of 94 preschoolers, and three distinct coping dimensions emerged: Positive Coping, Negative Coping - Emotional Expression, and Negative Coping - Emotional Inhibition. Further to this, Pang, Frydenberg, and Deans (2015) conducted a PCA on the CCS-R General Coping form, which was completed by parents of 119 preschoolers and obtained the same three coping dimensions as Yeo and colleagues. As coping research is currently hindered, in part, by the use of various measurement tools across various different age groups and stressors, with little replication, it was deemed useful to replicate the component structure of the CCS-R and/or conduct a CFA to confirm its factor structure (with an appropriately large sample size for a CFA).

\section{Coping and Mental Health}

The research on coping and mental health is unequivocal: how a person copes with stress predicts their mental health and psychological adjustment (Compas et al., 2001; Holen et al., 2012; Wright et al., 2010). Research on children's coping and mental health has generally focused on either general wellbeing or specific diagnoses, such as depression or anxiety (Thompson et al., 2010; Wright et al., 2010); few have focused on more general mental health. Additionally, most studies have explored the relationship between coping and mental health in clinical samples or children with a disability or serious illness (Babb, Levine, \& Arseneault, 2010; Dahlbeck \& Lightsey, 2008; Hema et al., 2009; Miller et al., 2009). With research suggesting that developmental outcomes may be more related to daily stressors than major life events (Compas, 1987; Valiente, Lemery-Chalfant, \& Swanson, 2009), an understanding of the relationship 
between coping and mental health in non-clinical populations may be important for elucidating effective coping patterns.

While individual studies vary, Compas et al.'s (2001) meta-review provides an overview of the general findings regarding coping and mental health in children and adolescents. Compas and colleagues found that engagement coping and problem-focused coping were associated with more positive adjustment. The coping subtypes most often associated with positive adjustment were problem solving, cognitive restructuring, and positive reappraisal of the stressors; these strategies reflect the ability to carefully analyse and problem solve a situation, the ability to focus on the positives during times of stress, and also the ability to generate alternative, more helpful thoughts about a situation (Compas et al., 2001).

Compas and colleagues reported that disengagement coping and emotion-focused coping were related to poorer adjustment. Specific coping strategies associated with poorer adjustment include avoidance (cognitive and behavioural), social withdrawal, resigned acceptance, emotional venting, wishful thinking, and self-blame/selfcriticism (Compas et al., 2001).

The limited research on coping and mental health in preschoolers suggests that the relationship may be similar to that observed in older children (Compas et al., 2001; Compas, Malcarne, \& Fondacaro, 1988; Sandler, Tein, \& West, 1994). It is important not to overlook these early years, considering research suggests that the prevalence of child psychiatric disorders and associated comorbidities is similar to that seen in later childhood (Egger \& Angold, 2006).

When it comes to anxiety, Yeo, Frydenberg, Northam, and Deans (2014) and Pang et al. (2015) found that those preschoolers who were rated higher on anxiety were more likely to engage in negative coping, particularly negative emotional expression, while preschoolers who rated lower on anxiety used more positive forms of coping. Regarding problem behaviour, as measured by the Child Behaviour Checklist (CBCL; Achenbach, 1991, 1992), Halpern (2004) found that preschoolers who used more problem approach coping had greater psychological adjustment, while children with more negative coping responses had higher internalising and externalising scores; other forms of coping, such as avoidance, passive acceptance and emotional venting, were not significantly related to problem behaviour.

The study reported here set out to replicate the three-component structure of coping in preschoolers (Positive Coping, Negative Coping - Emotional Expression, and Negative Coping - Emotional Inhibition) as measured by the CCS-R for General Coping, but also for two Situation Specific Coping forms (Saying Goodbye, such as to a parent, and Dislike, such as having to eat something not liked). Additionally, the article explores the relationships between different coping patterns and mental health in preschoolers, with mental health measured by the Strengths and Difficulties Questionnaire (SDQ).

\section{Method}

Participants

Participants were 132 parents of preschoolers enrolled at a university-affiliated Early Learning Centre (ELC) in Melbourne, Australia. Seventy-three (55.3\%) of the respondents were mothers of a preschooler and 59 (44.7\%) were fathers. For $56(73.7 \%)$ of the children, both parents responded. 
The mean age of the preschoolers was 55 months ( $S D=4$ months) and comprised of $31(40.8 \%)$ females and $45(59.2 \%)$ males; 68 (89.5\%) of the children had one or more siblings. Approximately $70 \%$ of the preschoolers were from an Anglo Australian background.

\section{Measures}

Child coping. Parents completed the CCS-R (Yeo et al., 2014). The CCS-R consists of 29 child-specific coping strategies (e.g., 'Get a teacher or grown-up to help') that parents rate on a 3-point Likert scale (never, sometimes, a lot). Parents rated the 29 coping strategies across three different situations: (1) general coping, (2) when their child has to say goodbye to their parent/s, and (3) when their child has to do something he/she does not like. According to Pang et al.'s (2015) research, the convergence of empirically derived factors with previous studies, along with the moderate-to-high reliabilities (.64 to .86) obtained, suggest the CCS-R has both construct validity and internal consistency.

Child mental health. Parents also completed the SDQ for 4- to 10-year-olds (Goodman, 2001) for their preschooler. The SDQ is a brief screening instrument for child and adolescent mental health and is used widely in both clinical and communitybased research (Goodman, Ford, Simmons, Gatward, \& Meltzer, 2003; Vostanis, 2006; Woerner et al., 2004). The SDQ is comprised of 25 questions that parents rate on a 3-point Likert scale (not true, somewhat true, certainly true) and the results typically derive five dimensions of children's mental health: emotional symptoms, conduct problems, hyperactivity/inattention, peer problems, and prosocial behaviour. Australian research with 4- to 9-year-olds obtained moderate-to-strong internal reliability across the five dimensions, along with good test-retest reliability and satisfactory external validity as measured against clinical diagnoses (Hawes \& Dadds, 2004).

\section{Procedure}

Parents of all preschoolers enrolled in 4- to 5-year-old kindergarten at the ELC were invited to participate in a larger study involving the evaluation of a newly developed classroom program targeted at improving social and emotional skills in preschoolers. Ethics approval was obtained from The University of Melbourne Human Research Ethics Committee (HREC:1135950) and consent for the project was obtained from the director of the ELC.

A series of principal component analyses (PCAs) was conducted on the three forms of the CCS-R: (1) to attempt to replicate the three-component structure of the General Coping form, and (2) to extend previous research by exploring whether this component structure could also be obtained for the two Situation Specific Coping forms (Saying Goodbye and Dislike).

Pearson product-moment correlations were then conducted to explore the relationships between types of coping (e.g., Positive Coping, Negative Coping - Emotional Expression, and Negative Coping - Emotional Inhibition, if supported by the PCAs) and mental health; with mental health measured by the subscales of the SDQ (e.g., Emotional Symptoms, Conduct Problems, Hyperactivity/Inattention, Peer Problems and Prosocial Behaviour). 
TABLE 1

Overall Measures of Intercorrelation for the Three CCS-R Forms

\begin{tabular}{|c|c|c|c|c|c|c|}
\hline & \multicolumn{2}{|c|}{ General Coping } & \multicolumn{2}{|c|}{$\begin{array}{c}\text { Situation Specific } \\
\text { Coping: Saying Goodbye }\end{array}$} & \multicolumn{2}{|c|}{$\begin{array}{l}\text { Situation Specific } \\
\text { Coping: Dislike }\end{array}$} \\
\hline & $\begin{array}{l}\text { Mothers } \\
(n=70)\end{array}$ & $\begin{array}{l}\text { Fathers } \\
(n=59)\end{array}$ & $\begin{array}{l}\text { Mothers } \\
(n=70)\end{array}$ & $\begin{array}{l}\text { Fathers } \\
(n=58)\end{array}$ & $\begin{array}{l}\text { Mothers } \\
(n=69)\end{array}$ & $\begin{array}{l}\text { Fathers } \\
(n=58)\end{array}$ \\
\hline Kaiser-Meyer-Oklin (KMO) & .58 & .66 & .61 & .59 & .61 & .52 \\
\hline Barlett's test of sphericity & $<.001$ & $<.001$ & $<.001$ & $<.001$ & $<.001$ & $<.001$ \\
\hline
\end{tabular}

\section{Results}

\section{Coping in Preschoolers}

The sample size for each PCA varied from 69 to 70 for mothers and 58 to 59 for fathers. Prior to performing the PCAs, the data were assessed for factorability using KaiserMeyer-Oklin's (KMO; Kaiser, 1970) measure of sampling adequacy and Bartlett's test of sphericity (Barlett, 1954); overall measures of intercorrelation indicated that the data was factorable (see Table 1).

\section{Extracting Components}

To determine the number of components to retain for each form of the CCS-R, the scree plot (Cattell, 1966), Kaiser's criterion (i.e., factors with an eigenvalue greater than 1; Kaiser, 1970), and the results of parallel analysis (Horn, 1965) were all examined. Parallel analysis is argued to be one of the most accurate methods for determining the number of components in PCA (Dinno, 2009; Stellefson \& Hanik, 2008). In the present research, the parallel analysis conducted yielded the most consistent and parsimonious number of components, indicating a three-component solution for the CCS-R.

Comparing two-, three- and four-component solutions. A series of PCAs with varimax rotation were performed for two-, three- and four-component solutions on all forms of the CCS-R to enable comparison with previous research (Hair, Black, Babin, \& Anderson, 2010). To ensure independence of the data, mother and father respondents were analysed separately. The PCAs found that a three-component structure of coping in preschoolers best fit the data for all forms of the CCS-R for mothers and fathers. A summary of the final three-component rotated solutions is displayed in Table 2.

Five of the six forms resulted in the hypothesised three components structure of: (1) Positive Coping, (2) Negative Coping - Emotional Inhibition, and (3) Negative Coping - Emotional Expression. The General Coping form for mothers was the exception, where the three components retained did not conform to the same component structure and the components produced poor to questionable reliability statistics. The reliability statistics for the two Situation Specific coping forms resulted in the most reliable components; particularly the Saying Goodbye form, and more so for mothers than fathers.

The items that loaded on the three components for all forms of the CCS-R were compared with previous findings to explore the degree to which the current PCAs aligned with previous research. Specifically, the items that loaded on the same components as Pang et al.'s (2015) findings were determined. These results are 
TABLE 2

Summary of the Final Three Component Solutions for the CCS-R

\begin{tabular}{|c|c|c|c|c|}
\hline & Component & $\begin{array}{l}\text { No. of } \\
\text { items }\end{array}$ & $\begin{array}{l}\text { Proportion of variance } \\
\text { explained }\end{array}$ & $\begin{array}{l}\text { Reliability } \\
\text { coefficient }\end{array}$ \\
\hline General Coping- & 1. Positive Coping - Active & 13 & $15.45 \%$ & .54 \\
\hline \multirow[t]{2}{*}{ Mothers } & 2. Positive Coping - Passive & 9 & $11.57 \%$ & .60 \\
\hline & 3. Negative Coping & 6 & $8.57 \%$ & .65 \\
\hline General Coping- & 1. Positive Coping & 12 & $19.71 \%$ & .65 \\
\hline \multirow[t]{2}{*}{ Fathers } & $\begin{array}{l}\text { 2. Negative Coping - } \\
\text { Emotional Expression }\end{array}$ & 8 & $11.16 \%$ & .74 \\
\hline & $\begin{array}{l}\text { 3. Negative Coping - } \\
\text { Emotional Inhibition }\end{array}$ & 7 & $9.31 \%$ & .09 \\
\hline Situation Specific & 1. Positive Coping & 14 & $22.17 \%$ & .89 \\
\hline $\begin{array}{l}\text { Coping: Saying } \\
\text { Goodbye - }\end{array}$ & $\begin{array}{l}\text { 2. Negative Coping - } \\
\text { Emotional Inhibition }\end{array}$ & 8 & $11.37 \%$ & .72 \\
\hline Mothers & $\begin{array}{l}\text { 3. Negative Coping - } \\
\text { Emotional Expression }\end{array}$ & 7 & $10.68 \%$ & .73 \\
\hline Situation Specific & 1. Positive Coping & 12 & $17.13 \%$ & .84 \\
\hline \multirow[t]{2}{*}{$\begin{array}{l}\text { Coping: Saying } \\
\text { Goodbye - Fathers }\end{array}$} & $\begin{array}{l}\text { 2. Negative Coping - } \\
\text { Emotional Inhibition }\end{array}$ & 7 & $12.55 \%$ & .57 \\
\hline & $\begin{array}{l}\text { 3. Negative Coping - } \\
\text { Emotional Expression }\end{array}$ & 8 & $11.68 \%$ & .76 \\
\hline Situation Specific & 1. Positive Coping & 13 & $16.57 \%$ & .84 \\
\hline \multirow{2}{*}{ Mothers } & $\begin{array}{l}\text { 2. Negative Coping - } \\
\text { Emotional Expression }\end{array}$ & 9 & $14.31 \%$ & .57 \\
\hline & $\begin{array}{l}\text { 3. Negative Coping - } \\
\text { Emotional Inhibition }\end{array}$ & 6 & $9.37 \%$ & .68 \\
\hline $\begin{array}{l}\text { Situation Specific } \\
\text { Coping: Dislike - }\end{array}$ & $\begin{array}{l}\text { 1. Negative Coping - } \\
\text { Emotional Expression }\end{array}$ & 7 & $15.07 \%$ & .74 \\
\hline \multirow[t]{2}{*}{ Fathers } & $\begin{array}{l}\text { 2. Negative Coping - } \\
\text { Emotional Inhibition }\end{array}$ & 10 & $13.95 \%$ & .31 \\
\hline & 3. Positive Coping & 11 & $13.06 \%$ & .75 \\
\hline
\end{tabular}

displayed in Tables 3 and 4. The Situation Specific Coping forms were the most consistent with previous research (Pang et al., 2015).

Coping and Mental Health

Data screening and cleaning. As the prior PCAs indicated that the Situation Specific Coping: Saying Goodbye form of the CCS-R had the most reliable components, three types of coping from this form and the five subscale scores for the SDQ (Goodman, 2001) were used for the correlation analyses. Only mothers' responses were analysed, as independent samples $t$ tests revealed no significant differences between mothers and fathers in their responses on the CCS-R or SDQ forms.

The descriptive statistics for the 70 responses on the CCS-R (Saying Goodbye form) and SDQ subscales are displayed in Table 5.

Pearson product-moment correlations. A series of bivariate Pearson product-moment correlations $(r)$ was conducted on the three types of coping and the five subscales of the SDQ to investigate the relationships between coping and mental health in preschoolers (Table 6). 
TABLE 3

Component Loadings for the CCSR and Comparison With Previous Research: Mothers

\begin{tabular}{|c|c|c|c|c|c|c|}
\hline & \multicolumn{6}{|c|}{ Form } \\
\hline & \multicolumn{3}{|c|}{$\begin{array}{l}\text { Situation Specific Coping: } \\
\text { Saying Goodbye }\end{array}$} & \multicolumn{3}{|c|}{$\begin{array}{l}\text { Situation Specific } \\
\text { Coping: Dislike }\end{array}$} \\
\hline & 1 & 2 & 3 & 1 & 2 & 3 \\
\hline \multicolumn{7}{|l|}{ 1. Positive Coping - Active } \\
\hline Have fun, play sport, draw, play games & .79 & & & .63 & -.37 & \\
\hline Play & .58 & & & .51 & & \\
\hline Chat to friends & .76 & & & .66 & & \\
\hline Work with others & .81 & & & .68 & & \\
\hline Work hard & .74 & .34 & & .49 & -.35 & \\
\hline Try to help others & .70 & & & .63 & & \\
\hline Be happy with the way things are & .63 & & & .41 & -.58 & \\
\hline Hope & .45 & & & .53 & & \\
\hline Spend a lot of time with a good friend & .70 & & & .66 & & \\
\hline Go out and play and forget about their problem & .48 & & & .65 & & \\
\hline Try & .65 & & & .57 & & \\
\hline Notice what others are doing & .46 & & & .45 & & \\
\hline Get a teacher or grown-up to help & .50 & & .34 & .47 & -.34 & \\
\hline \multicolumn{7}{|l|}{ 2. Negative Coping - Emotional Expression } \\
\hline 'Lose it' — cry, scream or fight & & .78 & & & .79 & \\
\hline Cry or scream & & .46 & & & .71 & \\
\hline Feel sad & -.36 & & .46 & & .47 & \\
\hline Get angry with others & & .64 & & & .71 & \\
\hline Keep away from other children & & & .52 & & & .68 \\
\hline Feel bad & & .53 & & & .55 & \\
\hline Blame themselves when things go wrong & & & .57 & & .53 & .37 \\
\hline Worry & & .51 & & & .38 & \\
\hline Get mad with themselves & & & .46 & & .62 & \\
\hline \multicolumn{7}{|l|}{ 3. Negative Coping - Emotional Inhibition } \\
\hline Keep feelings to self/not show how he/she feels & & & .78 & & & .64 \\
\hline Do nothing & & & .41 & & & .58 \\
\hline Don't let others know how they are feeling & & & .65 & & & .62 \\
\hline Get stomach aches or headaches & & .55 & & & & \\
\hline Give up & & & .59 & & & .52 \\
\hline Get sick & & .60 & & & & .37 \\
\hline Ask a teacher for help & .57 & & & .37 & & \\
\hline Consistent item loadings & 13 & 5 & 4 & 12 & 8 & 5 \\
\hline Total consistent items & & 22 & & & 25 & \\
\hline
\end{tabular}

Note: Only loadings $>.32$ are shown. The loadings of the components retained in the final solutions are in bold type. Primary loadings that were consistent with previous research (Pang et al., 2015) are in bold type and italics.

Positive Coping. A moderate positive correlation was obtained between Positive Coping and the Prosocial Behaviour subscale of the SDQ $(p<.01)$; this relationship explained $14 \%$ of the total variance.

Negative Coping - Emotional Inhibition. Three moderate positive correlations were obtained between Negative Coping - Emotional Inhibition (CCS-R) and the following subscales of the SDQ: Emotional Symptoms $(p<.01$, which explained $15 \%$ of the 
TABLE 4

Component Loadings for the CCSR and Comparison with Previous Research: Fathers

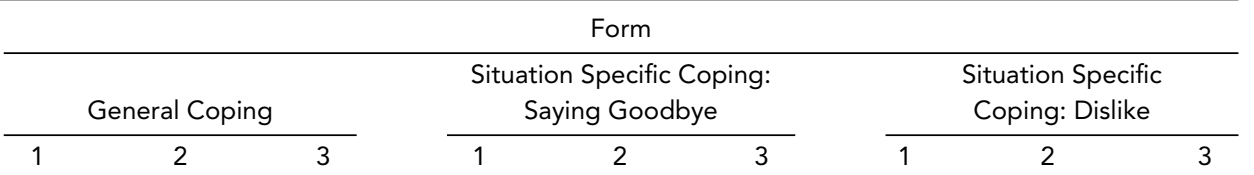

1. Positive Coping - Active

Have fun, play sport, draw, play games

\section{.62}

Play

Chat to friends

Work with others

Work hard

Try to help others

Be happy with the way things are

Hope

Spend a lot of time with a good friend

Go out and play and forget about their problem

Try

Notice what others are doing

Get a teacher or grown-up to help

2. Negative Coping - Emotional Expression

'Lose it' - cry, scream or fight

Cry or scream

Feel sad

Get angry with others

Keep away from other children

Feel bad

Blame themselves when things go wrong

Worry

Get mad with themselves

.61

.77

.79

.43

.55

.53

.77

.56

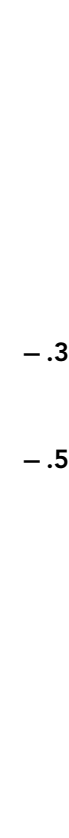

.66

.47

$-.36$

1

3

.46

$-34$

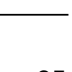

$\begin{array}{llll} & .46 & -.34 & -.35 \\ -.51 & .67 & & \\ & .53 & & -.33 \\ & .50 & & -.40 \\ & .48 & & -.34 \\ & & -.54 & -.46 \\ -.42 & .55 & & \\ -.41 & .46 & & -.63 \\ & & & -.37\end{array}$

$\begin{array}{ll}-.33 & .61 \\ -.42 & .52 \\ & .37 \\ & .75\end{array}$

$\begin{array}{ll} & .75 \\ -.37 & .71 \\ & .38 \\ & .56 \\ & \\ & .53 \\ & .57 \\ & .47 \\ & .62\end{array}$

\begin{tabular}{llll} 
& & .76 & \\
& & .78 & \\
.39 & & .75 & $*$ \\
.43 & & .81 & \\
.53 & & & .63 \\
& & .68 & \\
& .44 & & \\
.44 & .52 & .34 & .39 \\
& .43 & .52 & \\
\hline
\end{tabular}


TABLE 4

Continued

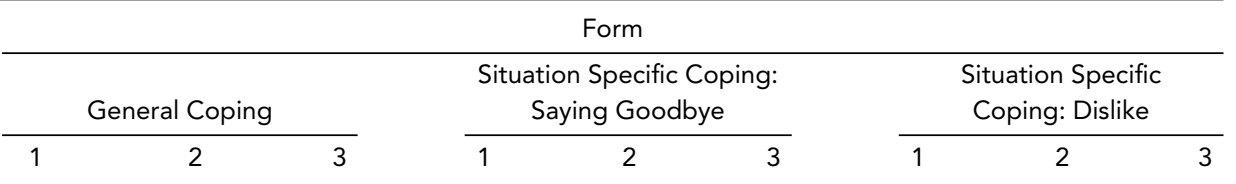

3. Negative Coping - Emotional Inhibition

Keep feelings to self/not show how he/she feels $\quad-.45$

Do nothing $\quad-.36$

Don't let others know how they are feeling

$-.36$

.54
.48
.63
.56
.78

Give up

Get sick

Ask a teacher for help

Consistent item loadings

20

$\begin{array}{ccc} & .57 & \\ 9 & 6 & 5 \\ 20 & 22 & 20\end{array}$

Note: Only loadings $>.32$ are shown. The loadings of the components retained in the final solutions are in bold type. Primary loadings that were consistent with previous research (Pang et al., 2015) are in bold type and italics. 
TABLE 5

Descriptive Statistics for the CCS-R (Situation Specific Coping: Saying Goodbye Form) and SDQ Subscales

\begin{tabular}{lcccc}
\hline & $\begin{array}{c}\text { Subscale } \\
\text { range }\end{array}$ & $\begin{array}{c}\text { Response } \\
\text { range }\end{array}$ & M & SD \\
\hline Positive Coping & $0-28$ & $4-28$ & 18.49 & 5.15 \\
Negative Coping — Emotional Inhibition & $0-16$ & $0-11$ & 3.76 & 2.42 \\
Negative Coping - Emotional Expression & $0-14$ & $0-9$ & 2.87 & 2.10 \\
SDQ - Emotional Symptoms & $0-10$ & $0-5$ & 1.64 & 1.55 \\
SDQ - Hyperactivity/Inattention & $0-10$ & $0-10$ & 3.20 & 2.49 \\
SDQ - Conduct Problems & $0-10$ & $0-7$ & 1.46 & 1.62 \\
SDQ - Peer Problems & $0-10$ & $1-8$ & 2.89 & 1.20 \\
SDQ - Prosocial Behaviour & $0-10$ & $3-10$ & 7.74 & 1.91 \\
SDQ - Total Score & $0-40$ & $3-21$ & 9.18 & 4.15 \\
\hline
\end{tabular}

TABLE 6

Pearson Correlations for the Relationships Between Coping and Mental Health $(n=70)$

\begin{tabular}{|c|c|c|c|c|c|c|}
\hline & \multicolumn{2}{|c|}{ Positive Coping } & \multicolumn{2}{|c|}{$\begin{array}{l}\text { Negative Coping - } \\
\text { Emotional Inhibition }\end{array}$} & \multicolumn{2}{|c|}{$\begin{array}{l}\text { Negative Coping - } \\
\text { Emotional Inhibition }\end{array}$} \\
\hline & $r$ & $\overline{\text { Sig. }}$ & $r$ & Sig. & $r$ & Sig. \\
\hline Emotional symptoms & -0.15 & .215 & $0.39 * *$ & .001 & 0.19 & .114 \\
\hline Hyperactivity/inattention & 0.04 & .766 & 0.03 & .839 & 0.03 & .789 \\
\hline Conduct problems & 0.07 & .564 & 0.13 & .275 & $0.24^{*}$ & .043 \\
\hline Peer problems & -0.10 & .429 & $0.30^{*}$ & .013 & -0.10 & .415 \\
\hline Prosocial behaviour & $0.37^{* *}$ & .002 & -0.16 & .185 & $-0.26^{*}$ & .030 \\
\hline Total score & -0.04 & .775 & $0.31^{* *}$ & .010 & 0.16 & .180 \\
\hline
\end{tabular}

Note: ${ }^{*}$ Indicates a significant correlation at $p<.05 ;{ }^{* *}$ Indicates a significant correlation at $p<.01$.

total variance), Peer Problems ( $p<.05$, which explained $9 \%$ of the total variance), and Total Score $(p=.01$, which explained $10 \%$ of the total variance).

Negative Coping - Emotional Expression. A weak positive correlation was obtained between Negative Coping - Emotional Expression (CCS-R) and the Conduct Problems subscale of the SDQ $(p<.05)$; this relationship explained $6 \%$ of the total variance. A weak negative correlation was obtained between Negative Coping Emotional Expression (CCS-R) and the Prosocial Behaviour subscale of the SDQ ( $p$ $<.05)$, which explained $7 \%$ of the total variance.

\section{Discussion}

How people cope with stress matters, for both physical and psychological wellbeing (Skinner et al., 2003). The present study adds to an understanding of how preschoolers cope by first replicating a three-component structure of coping in preschoolers, as measured by the CCS-R General Coping form; second, by extending on previous research by exploring the component structure of the CCS-R Situation Specific Coping forms (Saying Goodbye and Dislike) by analysing the responses from mothers and fathers separately with PCAs; and third, by examining the relationship between different coping patterns and mental health in preschoolers as measured by the SDQ. 
Coping in Preschoolers

Components. The three components obtained for five of the six forms (all three for fathers and the two Situation Specific Coping forms for mothers) are consistent with previous research on the CCS-R General Coping form (Pang et al., 2015; Yeo et al., 2014). The items that loaded on the three components of the Situation Specific Coping forms are largely consistent both between the Situation Specific Coping forms and with previous component analyses of the General Coping form (Pang et al., 2015; Yeo et al., 2014).

While larger sample sizes are preferred for factor and/or component analysis, the findings do suggest that the Situation Specific Coping forms are more robust at producing consistent and reliable components, particularly the Situation Specific Coping: Saying Goodbye form. One conclusion to draw from these findings is that measuring situation-specific coping, as opposed to general coping, is more accurate for a preschool population. The Situation Specific Coping: Saying Goodbye form is also arguably more specific than the Situation Specific Coping: Dislike form; the finding that the Saying Goodbye form was the more consistent and reliable of the two further supports the case for assessing coping in preschoolers in the most situation-specific manner possible. A second conclusion to draw is that the Situation Specific Coping: Saying Goodbye form resulted in the most robust component structure because saying goodbye is a more salient concern for preschoolers than the more general scenario of disliking something. This is supported by research on preschool populations that suggests that saying goodbye or separation from a parent is a very common concern for preschoolers (Chalmers et al., 2011, Halpern, 2004).

With both of these conclusions in mind, if only one measure of coping is feasible for a preschooler, an assessment of situation-specific coping based on the particular child's most salient issue would be the most appropriate and accurate measure of coping for that preschooler. A worthy consideration for future research would be to explore the component structure of the CCS-R using a situation-specific scenario that a child and/or parent had identified as a relevant concern for their child; for example, a parent could identify and complete the form with a scenario of their own choosing in mind, or a parent could select from a list of possible common situation-specific concerns for their preschooler. The present research suggests that a modification like this to the CCS-R may possibly lend itself to an even more robust component structure.

While the reliability of the components was higher for mothers than fathers on both of the Situation Specific Coping forms (Saying Goodbye and Dislike), considering the sample size was larger for mothers and arguably small for both types of respondents, it would be premature to suggest that the components were more reliable for mother than father respondents. However, even with the smaller sample size for fathers, the findings were reasonably consistent between mothers and fathers for both of the Situation Specific Coping forms, which is trending in a direction that suggests that mothers and fathers respond similarly when it comes to their preschooler's coping, at least when considering situation-specific coping.

Comparison with other studies. The components obtained in the present research for five of the PCAs are not consistent with adult dichotomies of coping; for example, problem- versus emotion-focused coping or primary- versus secondary-control strategies. Rather, Positive Coping, for example, was comprised of problem-focused 
coping (e.g, 'Work hard'), emotion-focused coping (e.g., 'Be happy with the way things are') and even secondary control strategies (e.g., 'Spend a lot of time with a good friend'). The lack of consistency between adult and child coping strategies is in line with previous research (Ayers et al., 1996; Walker et al., 1997). The lack of consistency with adult and adolescent research provides support for Compas et al.'s (2001) assertion that coping in children needs to be studied within the context of their age and/or developmental stage.

The components obtained in the present research do resemble those proposed by previous work on coping in preschoolers, namely, constructive coping, emotional venting, and passive coping (Blair, Denham, Kochanoff, \& Whipple, 2004; Eisenberg et al., 1993). These coping strategies for preschoolers have not been subject to factor analysis; however, they do parallel the dimensions obtained in both the present study and previous component analyses of the CCS-R (Pang et al., 2015; Yeo et al., 2014).

\section{Coping and Mental Health}

Positive coping. Consistent with the hypothesis, the Positive Coping component of the CCS-R (Saying Goodbye form) was positively associated with the one positive subscale of the SDQ, Prosocial Behaviour (example items include 'Considerate of other people's feelings' and 'Shares readily'). This result provides evidence of convergent construct validity for the Positive Coping component of the CCS-R as a dimension that reflects behaviours that are viewed as positive or socially acceptable by parents or caregivers. Of note, both positive coping and prosocial behaviour were arguably high in this population and may not necessarily be representative of a general population of preschoolers.

Negative coping. The Negative Coping - Emotional Inhibition component of the CCS-R (Saying Goodbye form) was positively associated with the Emotional Symptoms subscale of the SDQ (example items include 'Often complains of headaches ...' and 'Nervous and clingy'). This association, and the absence of an association with the more expressive subscale Conduct Problems, provides evidence of convergent construct validity that this component of the CCS-R reflects internalised or inhibited emotional symptoms rather than externalised or expressed emotional symptoms. Additionally, this component of the CCS-R was the only component that was significantly associated with both Peer Problems and Total Score for the SDQ. This suggests that emotional inhibition is the coping style most associated with both peer issues and greater issues overall (i.e., Total Score) in this population.

The Negative Coping - Emotional Expression component of the CCS-R was positively associated with the Conduct Problems subscale of the SDQ (example items include 'Often has temper tantrums ...' and 'Often fights with other children'), and this result provides evidence of convergent construct validity that this component of the CCS-R reflects externalised or expressed emotional symptoms. The negative correlation with this component of the CCS-R and the Prosocial Behaviours subscale of the SDQ indicates possible polar opposition between emotional expression and prosocial behaviour.

The findings for the two Negative Coping components of the CCS-R (Emotional Expression and Emotional Inhibition) suggest that both of these coping patterns are associated with negative emotions and/or behaviours in preschoolers. And while an association does not suggest causation, interventions designed to increase positive 
coping behaviours and/or decrease negative coping behaviours may be well targeted at reducing both emotional inhibition and expression; however, perhaps more so for emotional inhibition, due to its significant relationship with more issues overall (i.e., Total Score).

Other findings. A tentative explanation for the absence of a significant correlation between any of the CCS-R components and the Hyperactivity/Inattention subscale of the SDQ (example items include 'Restless, overactive ...' and 'Constantly fidgeting ...') is that these types of behaviours are not adequately covered by the CCS-R or any of the three components. Alternatively, hyperactivity/inattention may not be related to coping, positive or negative, in this particular, and arguably high functioning, group of preschoolers.

Comparison with other studies. The present findings on the relationship between coping and mental health (as measured by the SDQ) are consistent with the vast body of research that has found that positive coping is associated with more positive mental health and vice versa for negative coping (Compas et al., 2001; Frydenberg \& Lewis, 2009; Holen et al., 2012; Wright et al., 2010). The findings are also in line with research on preschoolers that has found positive coping to be associated with lower anxiety (Pang et al., 2015; Yeo et al., 2014) and reduced behavioural problems (Halpern, 2004), and negative coping to be associated with higher anxiety (Pang et al., 2015; Yeo et al., 2014). Halpern (2004), however, did not find a relationship between negative coping and increased behavioural problems, which is in contrast to the present findings.

Further to this, Compas and colleagues' (2001) meta-review on coping in children and adolescents found that engagement coping and problem-focused coping (akin to the Positive Coping component in the present research) were associated with more positive adjustment. However, in a few studies, engagement and problem-focused coping were associated with poorer adjustment when the stressor was subjectively or objectively uncontrollable (Compas et al., 2001). Saying goodbye to a parent is notably an uncontrollable situation, yet the present research found a positive relationship between positive coping and positive mental health (i.e., prosocial behaviour), which is in contrast to some of the studies analysed by Compas et al. (2001). A possible explanation for this finding is discussed below.

Compas and colleagues (2001) also found evidence for an association between negative coping (disengagement coping and emotion-focused coping) and poorer adjustment. Of note, Compas et al. (2001) found that disengaging from a stressor or one's emotions (similar to the Negative Coping - Emotional Inhibition component) and unregulated venting of emotions (similar to the Negative Coping - Emotional Expression component) were the most problematic coping strategies (Compas et al., 2001). The present research is in line with Compas et al.'s findings and the problematic nature of negative coping via emotional inhibition or emotional expression. Despite a few studies in Compas et al.'s meta-review finding disengagement and emotion-focused coping to be associated with better adjustment when a stressor was uncontrollable, this was not the case in the present research.

As the participants were from a single site, where many of the parent population were associated with the university affiliated with the centre, the responses may not be representative of a general population of 4- to 5-year-old preschoolers. In addition, all previous research on the CCS-R has utilised a very similar sample, which may 
be influencing the relatively consistent component structure for this scale. A further limitation of the present study was the sample size; ideally, a sample size of $>100$ cases is preferred for a factor/component analysis (Hair et al., 2010). A final limitation of note was that the CCS-R uses a 3-point Likert scale, which constrains the variability of responses that a larger Likert scale would permit.

\section{Conclusions}

The present research contributes to an understanding of coping in preschoolers. A three-component structure of coping in preschoolers was obtained consistently for all but one of the CCS-R forms (the General Coping form for mothers was the exception). These results provide confidence that coping strategies in preschoolers conform to the dimensions of (1) Positive Coping, (2) Negative Coping - Emotional Inhibition, and (3) Negative Coping - Emotional Expression, at least when utilising the CCS-R. The PCAs conducted also underscore the Situation Specific Coping forms as the most consistent and reliable for measuring coping in preschoolers, suggesting that coping in preschoolers is most accurately measured in a situation specific manner. The lack of consistency with the current components of the CCS-R and adult and adolescent coping research also highlights the need to study coping in children within the context of development. Further research on coping in preschoolers in still required, however, ideally with larger and more diverse samples. Additionally, confirmation of the component structure of the CCS-R by confirmatory factor analysis with an even larger sample size is recommended.

The relationships between coping and mental health (as measured by the SDQ) provide evidence of construct validity for the CCS-R components and support the vast and growing research that demonstrates that positive coping is associated with positive mental health and vice versa for negative coping. Additionally, for this sample of preschoolers, emotional inhibition coping was associated with greater mental health issues and may be a particularly appropriate area to target for coping interventions for this age group.

Together, the present research identifies that by age 4 , children have a repertoire of both positive and negative coping strategies and that these strategies are associated with greater or poorer adjustment respectively. With this in mind, the focus of interventions for this age group may be best targeted at teaching children a larger range of positive coping strategies and helping children to unlearn negative (e.g., emotional expression and emotional inhibition) coping strategies (Pang et al., 2015). Such an approach may be particularly promising for this age group, considering coping is understood to be more malleable in children than adults (Wadsworth et al., 2005). Explicit classroom instruction and/or parental education on how to identify existing coping strategies and, where appropriate, provide more positive strategies, are two intervention opportunities for this age group. And the CCS-R is one tool, with growing empirical validation, for helping to identify the positive (productive) coping strategies to be encouraged and developed in preschoolers, and also for recognising evidence of the negative (unhelpful) coping strategies to be unlearned where possible.

\section{Financial Support}

This research received no specific grant from any funding agency, commercial, or not-for-profit sectors. 


\section{Conflicts of Interest}

None.

\section{Ethical Standards}

The authors assert that all procedures contributing to this work comply with the ethical standards of the relevant national and institutional committees on human experimentation and with the Helsinki Declaration of 1975, as revised in 2008.

\section{References}

Achenbach, T.M. (1991). Manual for the Child Behavior Checklist/4-18 and 1991 profile. Burlington, VT: University of Vermont Department of Psychiatry.

Achenbach, T.M. (1992). Manual for the Child Behavior Checklist/2-3 and 1992 profile. Burlington, VT: University of Vermont Department of Psychiatry.

Ayers, T.S., Sandier, I.N., West, S.G., \& Roosa, M.W. (1996). A dispositional and situational assessment of children's coping: Testing alternative models of coping. Journal of Personality, 64, 923-958.

Babb, K. A., Levine, L.J., \& Arseneault, J.M. (2010). Shifting gears: Coping flexibility in children with and without ADHD. International Journal of Behavioral Development, 34, 10-23.

Barlett, M.S. (1954). A note on the multiplying factors for various chi square approximations. Journal of the Royal Statistical Society, 16(Series B), 296-298.

Blair, K.A., Denham, S.A., Kochanoff, A., \& Whipple, B. (2004). Playing it cool: Temperament, emotion regulation, and social behavior in preschoolers. Journal of School Psychology, 42, 419-443.

Cattell, R.B. (1966). The scree test for the number of factors. Multivariate Behavioral Research, 1, 245-276.

Chalmers, K., Frydenberg, E., \& Deans, J. (2011). An exploration into the coping strategies of preschoolers: Implications for professional practice. Children Australia, 36, 120-127.

Compas, B.E. (1987). Stress and life events during childhood and adolescence. Clinical Psychology Review, 7, 275-302.

Compas, B.E. (1998). An agenda for coping research and theory: Basic and applied developmental issues. International Journal of Behavioral Development, 22, 231-237.

Compas, B.E., Connor-Smith, J.K., Saltzman, H., Thomsen, A.H., \& Wadsworth, M.E. (2001). Coping with stress during childhood and adolescence: Problems, progress, and potential in theory and research. Psychological Bulletin, 127, 87-127.

Compas, B.E., Malcarne, V.L., \& Fondacaro, K.M. (1988). Coping with stressful events in older children and young adolescents. Journal of Consulting and Clinical Psychology, 56, 405-411.

Dahlbeck, D.T., \& Lightsey, O.R. (2008). Generalized self-efficacy, coping, and self-esteem as predictors of psychological adjustment among children with disabilities or chronic illnesses. Children's Health Care, 37, 293-315.

Deans, J., Frydenberg, E., \& Tsurutani, H. (2010). Operationalising social and emotional coping competencies in kindergarten children. New Zealand Research in Early Childhood Education Journal, 13, $113-24$

Dinno, A. (2009). Implementing Horn's parallel analysis for principal component analysis and factor analysis. The Stata Journal, 9, 291-298.

Egger, H.L., \& Angold, A. (2006). Common emotional and behavioral disorders in preschool children: Presentation, nosology, and epidemiology. Journal of Child Psychology and Psychiatry, 47, 313-337.

Eisenberg, N., Fabes, R.A., Bernzweig, J., Karbon, M., Poulin, R., \& Hanish, L. (1993). The relations of emotionality and regulation to preschoolers' social skills and sociometric status. Child Development, 64, 1418-1438.

Frydenberg, E. (2014). Coping research: Historical background, links with emotion, and new research directions on adaptive processes. Australian Journal of Psychology, 66, 82-92. 
Frydenberg, E. \& Lewis, R. (2009). Relations among well-being, avoidant coping, and active coping in a large sample of Australian adolescents. Psychological Reports, 104, 745-758.

Goodman, R. (2001). Psychometric properties of the Strengths and Difficulties Questionnaire. Journal of the American Academy of Child \& Adolescent Psychiatry, 40, 1337-1345.

Goodman, R., Ford, T., Simmons, H., Gatward, R., \& Meltzer, H. (2003). Using the Strengths and Difficulties Questionnaire (SDQ) to screen for child psychiatric disorders in a community sample. International Review of Psychiatry, 15, 166-172.

Hair, J.F., Black, W.C., Babin, B.J., \& Anderson, R.E. (2010). Multivariate data analysis: A global perspective (7th ed.). Upper Saddle River, NJ: Pearson Prentice Hall.

Halpern, L.F. (2004). The relations of coping and family environment to preschoolers' problem behavior. Journal of Applied Developmental Psychology, 25, 399-421.

Hawes, D.J., \& Dadds, M.R. (2004). Australian data and psychometric properties of the Strengths and Difficulties Questionnaire. Australian and New Zealand Journal of Psychiatry, 38, 644-651.

Hema, D.A., Roper, S.O., Nehring, J.W., Call, A., Mandleco, B.L., \& Dyches, T.T. (2009). Daily stressors and coping responses of children and adolescents with type 1 diabetes. Child: Care, Health and Development, 35, 330-339.

Hobfoll, S.E. (1989). Conservation of resources: A new attempt at conceptualizing stress. The American Psychologist, 44, 513-524.

Holen, S., Lervåg, A., Waaktaar, T., \& Ystgaard, M. (2012). Exploring the associations between coping patterns for everyday stressors and mental health in young schoolchildren. Journal of School Psychology, $50,167-193$.

Horn, J.L. (1965). A rationale and test for the number of factors in factor analysis. Psychometrika, 30, 179-185.

Kaiser, H.F. (1970). A second generation little jiffy. Psychometrika, 35, 401-415.

Miller, K.S., Vannatta, K., Compas, B.E., Vasey, M., McGoron, K.D., Salley, C.G., \& Gerhardt, C.A. (2009). The role of coping and temperament in the adjustment of children with cancer. Journal of Pediatric Psychology, 34, 1135-1143.

Pang, I., Frydenberg, E., \& Deans, J. (2015). The relationship between anxiety and coping in preschoolers. In P. Buchenwald \& K. Moore (Eds.), Anxiety, stress and coping (pp. 27-26). Berlin: Verlag.

Sandler, I.N., Tein, J.Y., \& West, S.G. (1994). Coping, stress, and the psychological symptoms of children of divorce: A cross-sectional and longitudinal study. Child Development, 65, 1744-1763.

Somerfield, M.R., \& McCrae, R.R. (2000). Stress and coping research: Methodological challenges, theoretical advances, and clinical applications. American Psychologist, 55, 620-625.

Skinner, E.A., Edge, K., Altman, J., \& Sherwood, H. (2003). Searching for the structure of coping: A review and critique of category systems for classifying ways of coping. Psychological Bulletin, 129, 216.

Skinner, E.A., \& Zimmer-Gembeck, M.J. (2007). The development of coping. Annual Review of Psychology, $58,119-144$.

Skinner, E.A., \& Zimmer-Gembeck, M.J. (2009). Challenges to the developmental studies of coping. In E.A. Skinner, \& M.J. Zimmer-Gembeck (Eds.), Coping and the development of regulation. New directions for child and adolescent development (pp. 5-17). San Francisco, CA: Jossey-Bass.

Stellefson, M., \& Hanik, B. (2008, February). Strategies for determining the number of factors to retain in exploratory factor analysis. Paper presented at the annual meeting of the Southwest Educational Research Association, New Orleans. Retrieved from http://files.eric.ed.gov/fulltext/ED500003.pdf

Thompson, R.J., Mata, J., Jaeggi, S.M., Buschkuehl, M., Jonides, J., \& Gotlib, I.H. (2010). Maladaptive coping, adaptive coping, and depressive symptoms: Variations across age and depressive state. Behaviour Research and Therapy, 48, 459-466.

Valiente, C., Lemery-Chalfant, K., \& Swanson, J. (2009). Children's responses to daily social stressors: Relations with parenting, children's effortful control, and adjustment. Journal of Child Psychology and Psychiatry, 50, 707-717.

Vostanis, P. (2006). Strengths and Difficulties Questionnaire: Research and clinical applications. Current Opinion in Psychiatry, 19, 367-372. 
Wadsworth, M.E., Raviv, T., Compas, B.E., \& Connor-Smith, J.K. (2005). Parent and adolescent responses to poverty-related stress: Tests of mediated and moderated coping models. Journal of Child and Family Studies, 14, 283-298.

Walker, L.S., Smith, C.A., Garber, J., \& Van Slyke, D.A. (1997). Development and validation of the pain response inventory for children. Psychological Assessment, 9(4), 392.

Woerner, W., Fleitlich-Bilyk, B., Martinussen, R., Fletcher, J., Cucchiaro, G., Dalgalarrondo, P., Mariko, L., \& Tannock, R. (2004). The Strengths and Difficulties Questionnaire overseas: Evaluations and applications of the SDQ beyond Europe. European Child $\backsim$ Adolescent Psychiatry, 13(Suppl. 2), 47-54.

Wright, M., Banerjee, R., Hoek, W., Rieffe, C., \& Novin, S. (2010). Depression and social anxiety in children: Differential links with coping strategies. Journal of Abnormal Child Psychology, 38, 405-419.

Yeo, K., Frydenberg, E., Northam, E., \& Deans, J. (2014). Coping with stress among preschool children and associations with anxiety level and controllability of situations. Australian Journal of Psychology, 66, 93-101. 